\title{
Abdominal Aortic Pathology Revealed by Cauda Equina Syndrome
}

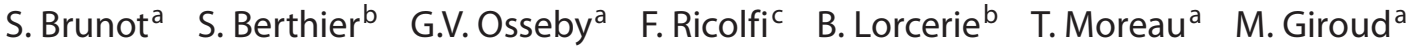 \\ Departments of ${ }^{\mathrm{a}}$ Neurology, ${ }^{\mathrm{b}}$ Internal Medecine and ${ }^{\mathrm{c}}$ Radioneurology, University Hospital Center, Dijon, France
}

Dear Sir,

Sixty percent of all arterial aneurysms involve the abdominal aorta, $75 \%$ of which occur in the infrarenal location [1]. Complications can include urinary or venous compression, ischemia by thromboembolic mechanisms or hemorrhage as a result of a rupture. According to the literature, neurological complications that occur in the perioperative or postoperative period are rare. We report 3 cases of patients who presented initial neurological symptoms as a result of aortic aneurysms.

Patient 1. A 61-year-old man with history of smoking (30 pack-years) and chronic alcohol abuse presented with acute motor and sensory deficits in the lower limbs. Clinical examination revealed a complete motor deficit of the left lower limb and a partial motor deficit of the right lower limb. The patient suffered from cruralgia and hypoesthesia of the left lower extremity. His deep tendon reflexes and the Babinski sign were absent. The anal reflex was diminished, but no saddle block anesthesia was observed. The distal pulses were not palpable. Lumbar medullar magnetic resonance imagery without diffusion (MRI) was normal except for a infrarenal abdominal aortic aneurysm measuring $7 \mathrm{~cm}$ in diameter, which was also visible on an abdominal computed tomography scan (CT scan; fig. 1). Three days later, electromyography confirmed peripheral involvement: F-waves were absent, nerve conduc- tion studies were normal and the recruitment was reduced in several myotomes in needle electromyography (EMG). An aorto-aortic endoprosthesis was implanted. Afterwards, he went to the rehabilitation department for the weakness of his left lower limb. His progress was satisfying despite persistent limping. He died 7 years later from the consequences of a prostheto-digestive fistula.

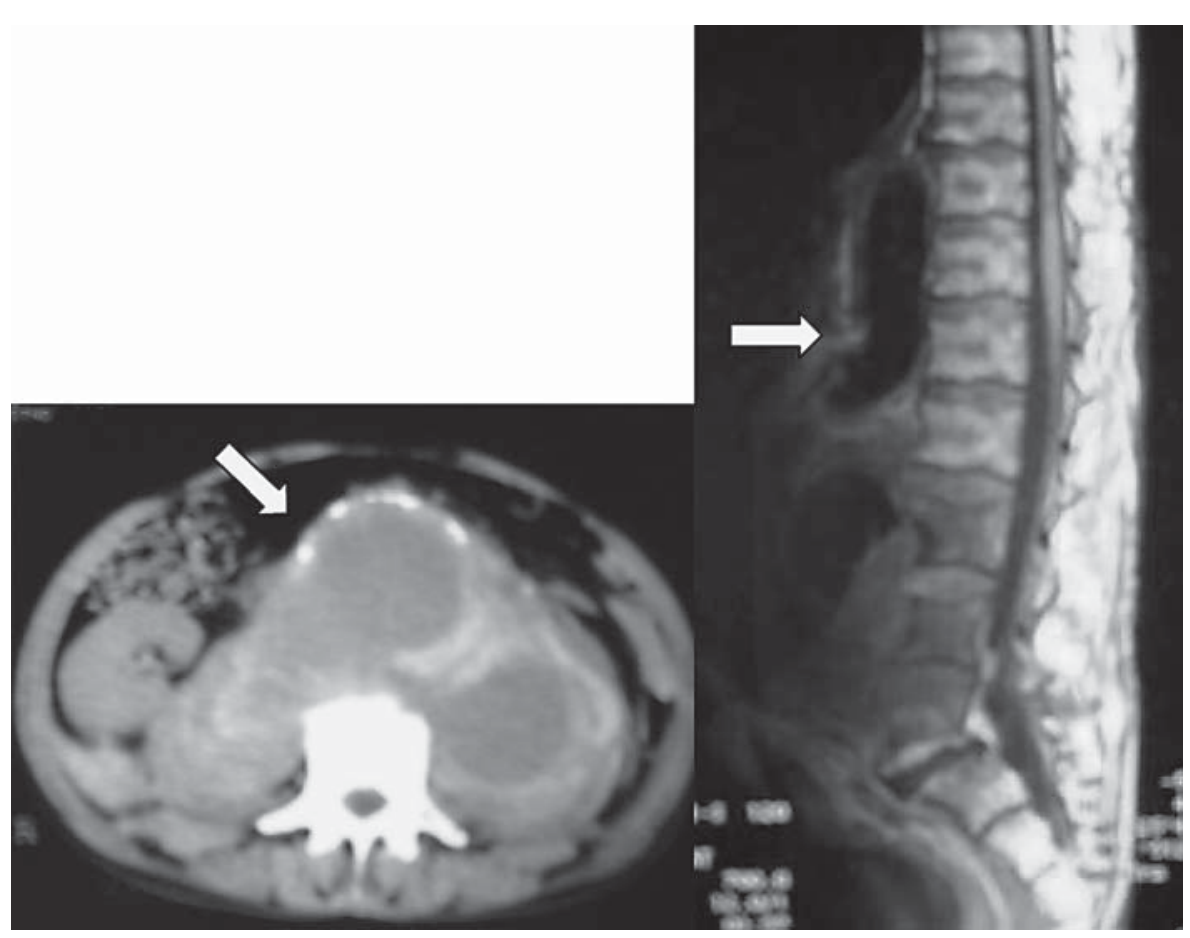

Fig. 1. Axial and sagittal abdominal CT scan: subrenal abdominal aorta aneurysm measuring $7 \mathrm{~cm}$ in diameter.

\section{KARGER}

Fax +4161306 1234 E-Mail karger@karger.ch www.karger.com
Dr. Brunot Sandrine

Department of Neurology, University Hospital Center

3 rue du Faubourg Raines

FR-21000 Dijon (France)

Tel. +33 038029 3753, E-Mail sandrinebrunot@ hotmail.com 
Patient 2. A 92-year-old man, without medical past history, presented with rapidly progressive flaccid paraplegia, bowel incontinence, acute urinary retention and sensory disorders reaching the first lumbar metamere. His deep tendon reflexes were absent and there was no Babinski sign. The medullar MRI without diffusion was normal but showed an infrarenal abdominal aorta aneurysm, which was confirmed by abdominal ultrasound. This aneurysm was partially thrombotic and its diameter was $5.5 \mathrm{~cm}$. Cauda equina syndrome was suspected. Because of his general state and age, no surgical treatment was considered and he died 3 months later of infectious complications related to his decubitus.

Patient 3. A 62-year-old man with history of hypertension and dyslipidemia presented with increasingly painful paresthesia, motor deficit of his amyotrophic lower limbs, saddle block anesthesia and urinary urgency. The onset was rapidly progressive. Deep tendon reflexes and the Babinski sign were absent. He described paresthesia approximately reaching the twelfth thoracic metamere. The distal pulses were not palpable. The medullar MRI without diffusion was normal, but the abdominal CT scan revealed thrombosis at the aortic bifurcation. We concluded that the patient had ischemic cauda equina syndrome. An aorto-bifemoral bypass was installed. His progress was satisfactory: progressive motor recovery, sensitive recuperation and his feet were hot and colored.

Cauda equina syndrome is associated with peripheral motor deficits of the lower limbs, sensory deficits with paresthesia, saddle block anesthesia and genitosphincterian disorders [2]. Ischemic cauda equina syndrome is a rare condition.

The artery of Adamkiewicz, or the great anterior radiculomedullary artery, is one of the most constant radicular arteries that arises between the fifth thoracic vertebra and the third lumbar vertebra $[3,4]$. This artery forms the anastomotic ansa of the conus and gives rise to the intradural filum terminale artery and other branches. Furthermore, these arteries anastomose with the iliolumbar artery, the median and lateral sacral arteries, and the hypogastric artery in order to provide vascularization to the intradural filum terminale, the cauda equina and the lumbosacral nervous roots (fig. 2) [5-8].

Aneurysms occur most frequently in the infrarenal aorta because the layers of the artery in this section are nourished by

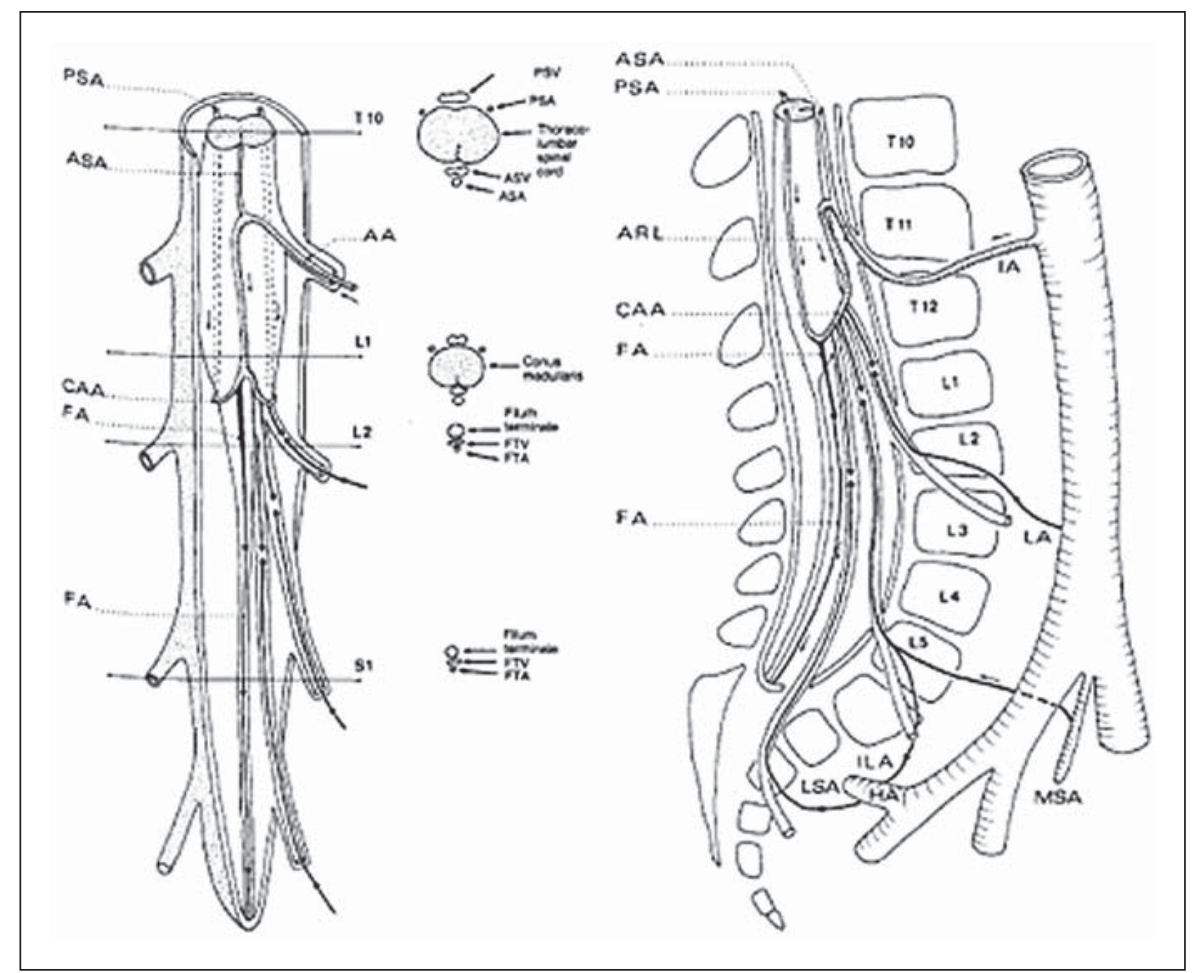

Fig. 2. Vascularization of the cauda equina (courtesy of Dr. Djindjian): anterior view and cross section and extraspinal nutrient arteries. ASA = Anterior spinal artery; PSA = posterior spinal artery; AA/ARL = artery of Adamkiewicz; CAA = cruciate anastomotic arcade; FA/FTA = filum artery; ASV = anterior spinal vein; PSV = posterior spinal vein; IA = intercostal artery; MSA = median sacral artery; ILA = iliolumbar artery; LSA = lateral sacral artery; $\mathrm{HA}=$ hypogastric artery.

the diffusion of nutrients from the arterial lumen and not by the vasa vasorum, which explains the thin arterial walls [1]. Atheroma is also more frequent in this part of the aorta and deterioration of the intima can lead to an aneurysm [1].

It is rare for aneurysms to be manifested by paraparesis, which can present as an indirect complication of surgical repair of the abdominal aorta aneurysm (1-2.8\%) [9-13] during which the arteries of the spinal cord are touched $[3,14]$. Our patients presented with cauda equina syndrome secondary to ischemia caused by an embolism of the cauda equina arteries via the artery of Adamkiewicz. Sometimes, the onset is progressive due to collateral supplies which arise in the suprarenal area $[4$, $13,14]$.

The differential diagnosis for rapidly progressive cauda equina syndrome mainly involves a vascular origin. Nonvascular pathologies can include a tumor, degener- ative disease of the spinal cord, arteriovenous malformation with a hematoma, lumbar stenosis (spondylolisthesis, slipped disc or degenerative) and Guillain-Barre syndrome $[3,4,7]$. When faced with a brutal and painful lumbosacral plexopathy in a diabetic patient, it is necessary to eliminate Bruns-Garland syndrome.

In regard to the second and third cases, an associated involvement of the spinal cord is possible because of sensory disorders up to T12 or L1 and complete motor weakness of the inferior limbs. Acute ischemia of the cauda equina, alone or associated to spinal cord ischemia, can be a complication of an abdominal aorta aneurysm.

\section{Acknowledgements}

We thank Philip Bastable and Emma Chavent, MD, for reviewing the English text. 


\section{References}

1 Crawford CM, Hurtgen-Grace K, Talarico E, Marley J: Abdominal aortic aneurysm: an illustrated narrative review. J Manipulative Physiol Ther 2003;26:184-195.

2 Goshgarian HG: Anatomy and function of the spinal cord; in Vernon WL (ed): Spinal Cord Medicine, Principles and Practice. New York, Demos Medical Publishing, 2003, pp 15-34.

-3 Donovan EM, Seidel GK, Cohen A: Painless aortic dissection presenting as high paraplegia: a case report. Arch Phys Med Rehabil 2000;81:1436-1438.

-4 Mallick IH, Kumar S, Samy A: Paraplegia after an elective repair of an infrarenal aortic aneurysm. J R Soc Med 2003;96:501-503.

-5 Djindjian M, Ribeiro A, Ortega E, Gaston A, Poirier J: The normal vascularisation of the intradural filum terminale in man. Surg Radiol Anat 1988;10:201-209.
6 Dommisse GF, Grobler L: Arteries and vein of the lumbar nerve roots and cauda equina. Clin Orthop 1976;115:22-29.

7 Parke WW, Gammell K, Rothman RH: Arterial vascularization of the cauda equina. Bone Joint Surg Am 1981;63:53-62.

8 Peppelenbosch N, Cuypers PW, Vahl AC, Vermassen F, Buth J: Emergency endovascular treatment for ruptured abdominal aortic aneurysm and the risk of spinal cord ischemia. J Vasc Surg 2005;42:608-614.

$\checkmark 9$ Dormal PA, Delberghe X, Roeland A: Infrarenal aortic aneurysm and spinal cord ischaemia. A new case and review of the literature. Acta Chir Belg 1995;95:136-138.

10 Etz CD, Luehr M, Kari FA, Bodian CA, Smego D, Plestis KA, Griepp RB: Paraplegia after extensive thoracic and thoracoabdominal aortic aneurysm repair: does critical spinal cord ischemia occur postoperatively? J Thorac Cardiovasc Surg 2008;135:324-330.
1 Fairhead JF, Phillips D, Handa A: Embolic spinal cord infarction as a presentation of abdominal aortic aneurysm. J R Soc Med 2005; 98:59-60

12 Nandeesh BN, Mahadevan A, Santosh V, Yasha TC, Shankar SK: Acute aortic dissection presenting as painful paraplegia. Clin Neurol Neurosurg 2007;109:531-534.

13 Joo JB, Cummings AJ: Acute thoracoabdominal aortic dissection presenting as painless, transient paralysis of the lower extremities: a case report. J Emerg Med 2000;19:333-337.

14 Joseph MG, Langsfeld MA, Lusby RJ: Infrarenal aortic aneurysm: unusual cause of paraparesis. Aust N Z J Surg 1989;59:743744 